\title{
Reconfigurando a Interação entre Ensino, Serviço e Comunidade
}

\section{Reshaping Interaction between Professional Training, Health Services, and the Community}

Janise Braga Barros Ferreira ${ }^{I}$ Aldaísa Cassanho Forster José Sebastião dos Santos ${ }^{I}$

\section{PALAVRAS-CHAVE: \\ - Educação Médica. \\ - Formação de Recursos Humanos. \\ - Atenção Primária. \\ - Serviços de Saúde. \\ - Participação Comunitária.}

\section{KEYWORDS:}

- Education Medical.

- Human Resources Training.

- Primary Care.

- Health Services.

- Community Participation.
Recebido em: 01/04/2010

Aprovado em: 26/08/2010

\section{RESUMO}

O Conselho Municipal da Saúde (CMS) de Ribeirão Preto (SP) conduziu discussões sobre os fundamentos da reconfiguração da interação entre a gestão local do Sistema Único de Saúde (SUS) e as instituições de ensino superior (IES), para promover a reorientação da formação profissional em saúde. Essa iniciativa local foi ao encontro das políticas indutoras nacionais, tais como o Promed, o Pró-Saúde e o PET-Saúde. O relato da experiência desse município expôs os interesses corporativos, políticos e econômicos dos agentes envolvidos. Ainda mostrou que o controle social e a cogestão foram potentes instrumentos para consolidar as instâncias democráticas de decisão, apontando o desafio de regular e avaliar o impacto dessa interação por meio de indicadores de saúde, ensino, pesquisa e de indices de satisfação dos usuários.

The Municipal Health Council in Ribeirão Preto, São Paulo State, conducted discussions on the principles for reshaping interaction between local management of the Unified National Health System (SUS) and institutions of higher learning in order to reorient professional training in health. This local initiative was consistent with national inductive policies such as Promed, Pró-Saúde, and PET-Saúde. The report on the experience in this city revealed the stakeholders' corporatist, political, and economic interests. It further demonstrated that social control and shared management were powerful instruments for consolidating the democratic decision-making levels, highlighting the challenge of regulating and evaluating the impact of this interaction through indicators for health, teaching, research, and user satisfaction. 


\section{INTRODUÇÃO}

No cenário nacional, a temática relacionada à reorientação da formação profissional em saúde, recomendando a inserção precoce dos estudantes das graduações da saúde na rede pública, principalmente nos serviços da Atenção Básica, tem sido alvo de intensos debates, tanto no meio acadêmico como no interior dos serviços de saúde e na comunidade. Este debate é complexo, comportando a inovação na formação do profissional do setor, que pretende ser integrada ao desenvolvimento da política pública de saúde nacional. Preconiza-se que a formação dos profissionais da saúde não se centralize apenas no locus hospitalar, mas seja mais ampla, com a vivência em outros cenários de produção de atenção à saúde e relacionada ao atendimento das demandas sociais. Este movimento está alinhado ao propósito de qualificar a atenção à saúde prestada pelo SUS de forma a concretizar os princípios de integralidade, equidade e participação social, e também ampliar o escopo da formação profissional em saúde ${ }^{1}$. O grande desafio, no entanto, é reconhecer que a integração ensino-serviço-comunidade implica a construção de um novo modo de ensinar, aprender e fazer que seja efetivo para todos os sujeitos deste processo: professores, estudantes, gestores das instituições de ensino superior (IES) e do SUS, profissionais da saúde e população.

Em seu eixo operativo, essa proposta encontra suporte em estratégias de mudanças curriculares nacionais e políticas indutoras derivadas de ação articulada entre os ministérios da Educação e Cultura (MEC) e da Saúde (MS), inicialmente focadas nos cursos de Medicina. Citamos o Programa de Incentivos às Mudanças Curriculares dos Cursos de Medicina (Promed), lançado em 2002, que apoiava as iniciativas de escolas médicas voltadas à reorganização curricular de seus cursos de Medicina ${ }^{2}$

O Promed destinava recursos financeiros para financiar acordos estabelecidos entre escolas médicas e o gestor local do SUS, a fim de propiciar a criação de cenários de práticas que permitissem a inserção do estudante de Medicina na rede extra-hospitalar de atenção à saúde. Com essa iniciativa, o MS vislumbrava a qualificação dos serviços de saúde e contribuía com as IES na formação de recursos humanos, premissa presente na Lei Orgânica da Saúde (LOS), nº 8.080/90³.

Entre as motivações para a reformulação do ensino médico encontrava-se o estudo realizado pela Comissão Interinstitucional Nacional de Avaliação do Ensino Médico (Cinaem). Entre outros achados, esse estudo concluiu que ao término da graduação em Medicina o futuro profissional não dominava a totalidade dos conteúdos essenciais à sua formação. Por isto, o programa propunha a revisão das práticas pedagógicas, enfatizando o emprego de metodologias ativas de ensino-apren- dizagem, a criação de novos cenários de ensino-aprendizagem externos ao ambiente do hospital universitário, o ingresso precoce dos alunos em ações de Atenção Básica à luz da medicina integral ${ }^{2}$. Assim, o Promed adquire destaque no contexto da educação médica brasileira, por propor alterações significativas no currículo médico, compartilhadas com diversas entidades, como o MEC, o MS, a Associação Brasileira de Educação Médica (Abem), a Associação Médica Brasileira (AMB), o Conselho Nacional de Secretários de Saúde (Conass) e o Conselho Nacional de Secretários Municipais de Saúde (Conasems), que se envolveram no processo.

A necessidade de provocar alterações na formação dos profissionais da saúde com vistas à qualificação da atenção à saúde, principalmente aquela ofertada pelo SUS, não se restringiu aos cursos de Medicina. Em 2005, o governo federal editou um novo programa que estendia as modificações curriculares aos cursos de Odontologia e Enfermagem e, em 2007, a todos os cursos de graduação da área da saúde. O Programa Nacional de Reorientação da Formação Profissional em Saúde (Pró-Saúde), produto de ação integrada do MS e MEC e apoiado pela Organização Pan-Americana da Saúde (Opas), objetivava "a integração ensino-serviço, visando à necessidade de incentivar transformações do processo de formação, geração de conhecimentos e prestação de serviços à comunidade, para a abordagem integral do processo de saúde-doença" ${ }^{\prime 4}$ (p. 1).

Em 2008, outra iniciativa federal, denominada Programa de Educação pelo Trabalho para a Saúde (PET-Saúde), veio ratificar as ações promotoras de integração ensino-serviço-comunidade descritas anteriormente. O PET-Saúde é reconhecido como uma estratégia do Pró-Saúde, tendo como foco o desenvolvimento da qualificação em serviço para os trabalhadores da saúde do SUS inseridos, preferencialmente, na Saúde da Família (SF). Esse programa estimula a aprendizagem tutorial, aproximando trabalhadores, alunos e docentes, a partir da vivência do trabalho em saúde na Atenção Básica, mais especificamente no trabalho desenvolvido pelas equipes de saúde da família ${ }^{5}$.

Reconhecendo o caráter instigante de tais iniciativas tanto para a formação em saúde quanto para a qualificação do sistema público de saúde, este relato propõe uma reflexão a partir da experiência de um município de médio porte na reconstrução de vínculos interinstitucionais em função das estratégias de política pública de saúde no tocante à reorientação da formação profissional para o setor.

\section{OBJETIVOS}

Este estudo, ciente de suas limitações pela grandeza do objeto tratado, registra o processo de reconfiguração das relações en- 
tre o gestor local, do SUS, e as instituições de ensino superior (IES) da área da saúde no município de Ribeirão Preto (SP), e pretende estimular a reflexão sobre possibilidades e dificuldades observadas ao longo do processo.

\section{MATERIAL E MÉTODOS}

O estudo foi realizado no município de Ribeirão Preto (SP), localizado na região nordeste do Estado de São Paulo, com população estimada de 559.651 habitantes (Datasus/TCU / 2007), pertencendo à área de abrangência do Departamento Regional de Saúde (DRS) XIII. Este DRS tem Ribeirão Preto como sede administrativa e abrange 26 municípios, com população estimada de 1.280.493 habitantes (Datasus/TCU/2007). É polo assistencial regional e, portanto, referência em ações e serviços de saúde de média e alta complexidade para a população dessa região. Outra característica do município é a presença em seu território de um hospital público terciário, de alta densidade tecnológica, sob gestão estadual, com abrangências regional, estadual e, em algumas áreas, nacional. A rede pública de saúde, além dos serviços próprios de Atenção Básica, secundária e terciária sob gestão municipal, conta com serviços públicos estaduais e serviços conveniados filantrópicos e privados para complementar a oferta assistencial.

Os materiais objetos de análise referem-se aos documentos (atas, relatórios) resultantes de painel, oficinas e reuniões do CMS e da participação dos autores nesse processo. O relato desta experiência apresenta a reconstrução da parceria interinstitucional, relacionando-a à política pública de saúde nacional, o SUS, à política municipal de saúde e às políticas interministeriais indutoras, tais como o Promed, o Pró-Saúde e o PET-Saúde.

\section{RESULTADOS}

O Conselho de Saúde, como dispõe a legislação orgânica do SUS (LOS no 8.142/90) ${ }^{6}$, é um "órgão permanente e deliberativo composto por representantes do governo, prestadores de serviço e profissionais de saúde e usuários, atua na formulação de estratégias e no controle da execução da política de saúde" (p. 1).

No caso de Ribeirão Preto, o Conselho Municipal de Saúde (CMS) é um colegiado bastante ativo e, de 2003 a 2005, motivado pela iniciativa do MEC e do MS de induzir a reorientação da formação profissional em saúde, promoveu discussões sobre os fundamentos da relação entre a SMS, gestora local do SUS, e as IES do campo da saúde. A temática central foi a reconfiguração das relações entre essas instituições, no território local, para a conformação de cenários de práticas acadêmicas integrados à rede pública de serviços de saúde.
O CMS insistia na realização de amplos debates sobre as novas bases da parceria, considerando que, inevitavelmente, os cenários de prática seriam ampliados, pois estudantes de diversos cursos de graduação da saúde deveriam ser inseridos mais precocemente em vivências extra-hospitalares em decorrência de reformulações das políticas públicas de educação e saúde no tocante à formação profissional nesse setor. Esse colegiado justificava sua insistência alegando que, em outros momentos, foram vivenciadas experiências pouco satisfatórias de aproximação das IES com os serviços de saúde, advindo deste fato a necessidade de amadurecimento dessa iniciativa antes da celebração de novos ajustes. As argumentações do CMS abrangiam ainda a necessidade de definições precisas relativas ao modelo de inserção no campo desses alunos, as contrapartidas a serem efetuadas pelas IES e pelo gestor local do SUS, e a forma de participação social no projeto.

O município, à época, apresentava seu terrítório dividido em cinco Distritos de Saúde, abrigava cinco IES da área da saúde (uma pública e quatro privadas) e três cursos médicos (um público e dois privados), além de vários cursos de graduação do setor (Enfermagem, Odontologia, Farmácia, Nutrição, Fisioterapia, Terapia Ocupacional, Psicologia, etc.).

Essas instituições, inevitavelmente, iriam acessar a rede pública de saúde para proporcionar os ambientes de prática a seus alunos, como recomendavam as portarias interministeriais da Educação e da Saúde.

É fato a existência anterior, no município, de parcerias entre o gestor público local de saúde e IES do setor. Para exemplificar, citamos a instituição pública que, desde 1956, desenvolvia atividades extramuros se fazendo presente na comunidade por meio de práticas de ensino e pesquisa, estendendo posteriormente essa ação às práticas assistenciais em centros de saúde escola ${ }^{7}$. Nesses centros, desde 1979, quando foi criado o primeiro centro de saúde escola, neste município, a referida instituição desenvolvia ações de assistência-ensino-pesquisa, abrangendo a Atenção Básica e especializada, incorporando, mais tarde, a atenção às urgências e emergências para uma área de abrangência distrital. No início de 2000, essa IES incrementou sua atuação na Atenção Básica da rede municipal, implantando conjuntamente com a SMS cinco (5) núcleos de saúde da família. Com o tempo, foram abertas outras IES do setor no município, que, por meio de convênios, ainda que em menor proporção, promoveram a inserção de seus estudantes e docentes em unidades de Atenção Básica e secundária na rede de saúde pública local. Para a complementação assistencial do SUS havia também parcerias para atendimento hospitalar em entidades públicas e/ou privadas sediadas no território municipal. Todas estas relações, do ponto de vista formal, 
estavam legalmente estabelecidas por meio de convênios. No entanto, apesar de atenderem às exigências legais, esses convênios pouco discutiam o modus operandi desse processo.

Naquele momento, diante da perspectiva de expansão dessa parceria, os conselheiros municipais da saúde entenderam como essencial a explicitação de suas diretrizes norteadoras a fim de garantir legitimidade ao processo e transparência às negociações.

Concretamente, a primeira ação do CMS foi a promoção de um painel, em 2003, intitulado "A relação entre universidades sediadas no município de Ribeirão Preto-SP e a Secretaria Municipal da Saúde, gestora do SUS". O painel comportou a discussão de vários temas, como: a proposta da SMS para a criação dos Distritos de Saúde Escola (DSE); os aspectos jurídicos da parceria entre as IES e a SMS: quais instrumentos utilizar para construir contratos e relações interinstitucionais?; os aspectos éticos da parceria entre as IES e a SMS: ética dirigida para as relações interinstitucionais; modelos de atividades administrativas e assistenciais para os DSE: a proposta das IES públicas e privadas e a visão da SMS. Este painel contou com uma participação ativa e ampliada da sociedade, representada por trabalhadores da saúde, Ministério Público, Conselho Regional de Medicina do Estado de São Paulo, sindicatos do setor saúde, Departamento Regional de Saúde XIII, dirigentes, docentes e discentes das IES da área da saúde e membros do CMS.

Havia resistência de alguns segmentos do CMS à criação, no município, dos Distritos de Saúde Escola (DSE), delimitando a atuação das IES do setor saúde em áreas geográficas distintas, sem uma definição das bases da parceria. A resistência era mais explícita em referência às IES privadas, sob o questionamento de que haveria uma terceirização das ações e da gestão do sistema de saúde. Inicialmente, foi pequena a repercussão, entre os conselheiros, da estreita relação existente entre as políticas ministeriais e a expansão da parceria interinstitucional proposta pela SMS.

Assim, o apoio do CMS à constituição dos DSE se vinculou à definição dos aspectos jurídicos, administrativos, assistenciais, de ensino e pesquisa. Após a realização do painel, foram organizadas, nos Distritos de Saúde, oficinas de trabalho para divulgar, detalhar e debater as propostas. O trabalho desenvolvido nessas oficinas, ocorridas no primeiro semestre de 2004, foi embasado nos relatórios desse painel, envolvendo novamente todos os atores interessados no processo: trabalhadores da saúde, professores, alunos, gestores institucionais e segmentos da comunidade.

Em decorrência dessas oficinas, formou-se um grupo multiprofissional e interinstitucional composto por represen- tantes de cada entidade envolvida, que produziu, coletivamente, após seis meses de trabalho, uma minuta de convênio para fundamentar e ordenar a implementação da parceria. A discussão com os sindicatos dos trabalhadores da saúde e o poder legislativo municipal se estendeu, e o CMS aprovou, no final de 2004, os termos para o novo ajuste. A tramitação no poder legislativo municipal foi arrastada, pois afloraram muitos conflitos de interesses. Somente no final de 2005, foi aprovada a lei que autorizava a celebração de convênio da SMS com as IES da área da saúde. Essa lei (10.551/2005) discriminava a contrapartida econômico-financeira das instituições e as corresponsabilidades no desempenho assistencial, educacional e de produção de conhecimento.

\section{DISCUSSÃO}

Ao longo de três anos, todo o processo foi marcado por intensos debates e conflitos corporativos, políticos e econômicos das mais variadas ordens. Nesse sentido, a vivência desta experiência expôs algumas situações que influenciaram decisivamente seu trajeto e desfecho.

Embora a iniciativa da gestão local estivesse respaldada nas políticas indutoras governamentais, tais como o Promed e o Pró-Saúde, a própria Lei Orgânica do SUS (LOS 8.080/90) indicava que:

os serviços públicos que integram o Sistema Único de Saúde - SUS constituem campo de prática para ensino e pesquisa, mediante normas específicas, elaboradas conjuntamente com o sistema educacional; a responsabilidade do sistema quanto à ordenação da formação de recursos humanos na área da saúde e a organização de um sistema de formação de recursos humanos em todos os níveis de ensino, inclusive de pós-graduação, além da elaboração de programas de permanente aperfeiçoamento de pessoal $^{3}$.(p.29)

No início da discussão, a gestão local do SUS, representada pela SMS, mostrava-se favorável ao incremento desta parceria e para tanto elaborou a proposta consoante os preceitos do Promed. A proposta da SMS com a cessão do campo às IES se fundamentou na assunção da responsabilidade do SUS para com a formação de recursos humanos, vislumbrando nessa interação a construção de uma efetiva contribuição para a sua qualificação. Nessa ótica, a expansão da parceria para serviços de Atenção Básica e secundária e a conformação de novas relações no interior da rede foram assumidas como uma diretriz da política de saúde local, incorporada ao Plano Municipal da Saúde. 
Em contrapartida, segmentos do CMS questionavam a generalidade e a pequena divulgação da proposta. Alguns conselheiros sustentavam que as IES apenas se utilizavam do campo de estágio em função de seus interesses específicos, sem o compromisso de avaliar e disseminar os resultados dessa atuação e de seu impacto para a melhoria das condições de saúde da população. No entanto, a abordagem diferenciada desse processo, manifesta na congregação e participação ativa de vários atores sociais em torno do problema, resultou em um produto concreto, representado por um instrumento jurídico diferenciado, que traduziu, de certa forma, os múltiplos anseios dos participantes. Podemos afirmar que o instrumento inovou, ao englobar, além de exigências jurídicas usuais, cláusulas específicas sobre ações de ensino, pesquisa, assistência, gestão e participação social a serem compartilhadas pelos parceiros.

Os pontos conflitantes para o estabelecimento da parceria foram muitos. No entanto, destacamos três situações representativas da vivência desse processo e os respectivos encaminhamentos.

\section{Situação 1: Necessidade de Investimentos para Adequação Tecnológica e Arquitetônica da Rede de Saúde}

A estrutura física da rede de saúde apresentava inconformidades, em sua ambiência, quanto à conformação de uma rede de saúde escola, o que poderia impactar negativamente tanto a assistência quanto as atividades de ensino. O CMS enfatizou essa questão, e havia um entendimento mais global de que as IES deveriam arcar com o financiamento das intervenções estruturais, principalmente nos locais de sua maior atuação. O CMS apresentou essa exigência mais incisivamente às IES privadas, sem isentar a participação financeira das instituições públicas.

É certo que, se a meta da interação ensino-serviço-comunidade passa por proporcionar condições de ensino-aprendizagem garantindo-se a assistência de qualidade, era preciso considerar a análise de ocupação, ampliação e construção de novos espaços assistenciais e de ensino. A construção de uma rede-escola, do ponto de vista estrutural, carece de investimentos de médio e longo prazo. De certa forma, a adesão ao Pró-Saúde contribuiu para conduzir essa questão, já que os contemplados pelo programa recebiam recursos financeiros que viabilizavam um investimento estrutural e tecnológico na rede de saúde. Um fato interessante observado foi a dificuldade de levantar as necessidades de investimento de forma a contemplar um planejamento em função dos objetivos da parceria, uma vez que os atores, embora fisicamente juntos, defendiam suas lógicas particulares de organização do trabalho.
Entretanto, a interação induzida pelo Pró-Saúde foi determinante para favorecer a relação interinstitucional, uma vez que os projetos, necessariamente, derivariam de uma produção conjunta da gestão municipal e das IES. O Pró-Saúde abriu caminho para a compreensão de que aquele momento era diferenciado porque em uma mesa conjunta de negociação os interesses de cada um deveriam compor uma necessidade maior, à qual os investimentos seriam direcionados. A política indutora no município certamente imprimiu uma nova dinâmica na relação interinstitucional, criando uma roda de conversação que acolheu gestores, trabalhadores, estudantes e usuários em torno da complexa missão de convergência de interesses e saberes. A essência da discussão remeteu à compreensão, por todos os agentes, de que não se tratava apenas de construir salas e adquirir equipamentos, mas, sim, de ter clareza sobre quais seriam a ambiência e a incorporação tecnológica, indispensáveis à reorganização da produção do cuidado, à reorientação da formação profissional e, consequentemente, ao alcance das metas educacionais e da qualificação da atenção prestada.

\section{Situação 2: Necessidade de Definir o Modelo de Inserção dos Alunos nos Cenários de Prática}

Por indicação do CMS, o modelo de inserção dos alunos deveria ser construído conjuntamente com os profissionais dos serviços em função das necessidades de usuários, estudantes, professores e trabalhadores, segundo as diretrizes do MEC e do MS por meio de suas políticas.

A complexidade dessa temática estava refletida na realidade da rede, que, naquele momento, discutia concomitantemente a revisão do modelo de atenção e a expansão do processo de ensino-aprendizagem para os serviços básicos e secundários - ambas as situações com direto envolvimento desses atores e de suas práticas. Também havia a participação do usuário, que reclamava a compreensão desse novo arranjo assistencial e de ensino, e de suas repercussões sobre a assistência à sua saúde.

Muitos trabalhadores não se sentiam à vontade com a presença dos alunos e dos docentes e não reconheciam como suas as responsabilidades dessa ação, já que seus contratos de trabalho não mencionavam a função docente. Em alguns momentos, a reivindicação de remuneração para desenvolver essas atividades era verbalizada por todas as categorias profissionais e encontrava dificuldade em ser executada, em virtude das características contratuais de cada organização. Essa vivência foi registrada por outros autores quando descreveram construções processuais semelhantes. Forster ${ }^{8}$ (p. 85), ao apresentar a experiência da Universidad Autónoma de Madrid, 
na Espanha, na formação em Atenção Primária e medicina de família, no curso de Medicina, cita a "criação de vagas de professores associados nos centros de saúde" pela universidade, com remuneração específica para o desenvolvimento dessa função pelo médico. Cabral et al. ${ }^{1}$ ratificam esse impasse com a demonstração da implantação de "uma forma de retribuição pecuniária aos profissionais dos serviços que se engajassem no programa na qualidade de preceptores" (p. 376).

Em contrapartida, também havia colaborações pontuais de trabalhadores em função das inserções no campo que já ocorriam em algumas unidades de saúde e rotineiramente nas unidades ligadas às IES, havia algum tempo, com várias experiências de sucesso.

Por outro lado, no interior das IES, a aproximação mais intensa com a comunidade e o deslocamento de práticas de ensino para os cenários da Atenção Básica também suscitavam manifestações diferenciadas, como afirmam Franco et al.7: "a necessidade/disposição de ir à comunidade, entretanto, é honesto que se diga, não era unanimidade nem dentro dos próprios Departamentos de Medicina Preventiva, muito menos das Escolas Médicas, como, aliás, ainda acontece nos dias atuais" (p. 429).

Deste modo, um dos desafios postos às IES do campo da saúde é a descoberta de práticas inovadoras de ensino e assistência que transcendam a transferência de rotinas do ambiente nosocomial para a rede extra-hospitalar e estejam conectas às necessidades dos serviços de Atenção Básica e secundária. De acordo, com Gil et al. ${ }^{9}$, "a formação dos futuros médicos e profissionais de saúde precisa ir além das práticas atuais e avançar no delineamento dos possíveis cenários sociais nos quais estarão inseridos os atuais estudantes [...]"(p. 231).

Naquele momento, o que se propunha era uma transformação que incitava a uma união de esforços para que a rede assistencial se tornasse uma rede-escola, com todas as suas vantagens e dificuldades, que deveriam ser assumidas de forma coletiva. A discussão iniciada pelo CMS ao rever detalhadamente essa interação institucional, com a incorporação das novas tendências da formação do profissional da saúde e de outros membros da equipe de saúde, definiu alguns compromissos que foram incorporados no instrumento legal, tais como o fornecimento de cestas básicas aos agentes comunitários de saúde que desenvolvessem atividades com alunos das graduações da saúde. Posteriormente, o surgimento do PET-Saúde e a possibilidade, por meio do exercício de educação permanente, de transferir um incentivo financeiro aos docentes, trabalhadores (tutores) e estudantes foram ao encontro de algumas aspirações desses atores e, de certa forma, representaram um estímulo à consolidação dessa interface entre as IES e a rede básica do SUS.

\section{Situação 3: Retomada da Gestão Colegiada em Toda a Rede de Saúde sob Gestão Municipal}

Para enfrentar a situação da reconstrução dos vínculos interinstitucionais nos moldes propostos pelo CMS, discutiu-se a implantação de novos mecanismos e instrumentos de participação, mais democráticos, que contemplavam a inclusão de trabalhadores da saúde, usuários, gestores, professores e estudantes, reconhecendo que a atuação integrada desses atores sociais teria potência para promover alterações e reconduzir a dinâmica dessa relação. Em 2003, iniciou-se o exercício de algumas práticas mais participativas de gestão em diferentes espaços de trabalho da SMS, embrião da Proposta de Gestão dos Serviços da Secretaria Municipal da Saúde de Ribeirão Preto, implantada, em 2005, com o objetivo principal de utilizar uma visão estratégica participativa para abordar a gestão da produção em saúde envolvendo os atores citados, com a aprovação do CMS. Tratava-se de fato relevante, pois esta situação proporcionou a interface da proposta de gestão colegiada com o incremento da parceria entre a SMS e as IES da área da saúde, as quais passaram a ter representatividade nos colegiados distritais, contando com a presença dos usuários do SUS. A cogestão permitiu refletir acerca das relações no processo de trabalho das unidades de saúde. No entanto, tem-se o reconhecimento de que esse formato de gestão carece de investimento, pois a solidez de processos participativos pressupõe mudanças conceituais, de comportamento e de condições institucionais favoráveis ao seu desenvolvimento.

A lição aprendida indicou que a existência de instrumentos legais que respaldem as relações é importante, mas não garante, por si só, o sucesso da parceria. Há necessidade de transposição conjunta de barreiras para construir uma trajetória que promova a transformação e o comprometimento dos agentes implicados com as demandas sociais - neste caso, em particular, as do SUS, que adotam a visão ampliada do conceito de saúde, levando em conta seus determinantes sociais ${ }^{9}$. Para tanto, as discussões devem abordar quais serão os caminhos facilitadores desse processo integrativo para o desenvolvimento do ensino-aprendizagem e de produção de ações de saúde e de pesquisa, a partir da compreensão das complexidades encerradas nesse contexto, oriundas da diversidade de seus sujeitos e de suas realidades, elementos que precisarão ser conjuntamente recompostos.

\section{A TÍTULO DE FINALIZAÇÃO}

Todo este conflituoso processo pautou-se pela busca de maior interação ensino-serviço, visando à reorientação da formação profissional em saúde, por meio de uma abordagem integral do processo saúde-doença, com ênfase na Atenção Básica, a partir da promoção de atitudes transformadoras compromis- 
sadas com a geração de conhecimentos, o processo de ensinoaprendizagem e a prestação qualificada de serviços de saúde à população.

A experiência do município de Ribeirão Preto expôs os interesses corporativos, políticos e econômicos dos agentes envolvidos e a inadequação da rede de atenção para o desenvolvimento das práticas de ensino. Esta vivência ainda revelou que as IES do campo da saúde precisariam desenvolver a capacidade de atendimento das necessidades de saúde e não só do tratamento de doenças. A aproximação mais estreita entre as IES da área da saúde, parceiras da SMS, e as equipes de saúde foi fundamental para difundir a superação da visão simplesmente acadêmica dos campos de estágio para uma visão de responsabilidade compartilhada na formação de recursos humanos para o setor.

O instrumento jurídico foi além de causas conveniais administrativas, englobando a cogestão e aspectos do ensino, da pesquisa e da assistência a serem compartilhados pelas instituições. A necessidade de construir parcerias sustentáveis encontrou na gestão colegiada um grande canal para o seu fortalecimento. O caráter processual dessa temática permitiu, ao longo desse período, a observação da convergência das políticas indutoras interministeriais, tais como o Promed, o Pró-Saúde e o PET-Saúde, às diretrizes da política municipal de saúde e às do SUS no tocante à reorientação da formação profissional em saúde.

Certamente, o protagonismo do CMS foi o diferencial disparador desse processo, na medida em que mobilizou vários atores sociais em um modo de interação institucional mais participativo e reflexivo, na perspectiva da formação profissional, da produção do cuidado, do conhecimento em saúde e da participação e controle social.

Nesse cenário, o controle social e a cogestão presentes se mostraram potentes para consolidar instâncias democráticas de decisão e apontaram a necessidade de criar mecanismos e instrumentos para regular e avaliar o impacto dessa parceria por meio de indicadores de saúde, de pesquisa e de índices de satisfação dos usuários.

\section{REFERÊNCIAS}

1. Cabral PE, Machado JLM, Machado VMP, Pompilio MA, Vinha JM, Ayach WM, Mattos MCI. Serviço e comunidade, vetores para uma formação em saúde: o curso de medicina da Uniderp. Rev Bras Educ Med. 2008;32(3):374-82. Brasil. Ministério da Saúde. Portaria n⿳0 610, de 26 de março de 2002. Disponível em: http://www.saude.gov.br/sas/. htm >. Acesso em: 30 set. 2009.

2. Brasil. Ministério da Saúde. Lei $\mathrm{n}^{\circ}$ 8.080, de 19 de setembro de 1990. Dispõe sobre as condições para a promoção, prote- ção e recuperação da saúde, a organização e o funcionamento dos serviços correspondentes e dá outras providências. Gestão Municipal da Saúde: leis, normas e portarias atuais. Rio de Janeiro: Brasil. Ministério da Saúde, 2001. p. 29.

3. Brasil. Ministério da Saúde. Portaria Interministerial $\mathrm{n}^{\mathrm{o}}$ 2.101, de 03 de novembro de 2005. Disponível em: <http:/ / www.saude.gov.br/sas/.htm>. Acesso em: 25 out. 2009.

4. Brasil. Ministério da Saúde. Portaria n. ${ }^{\circ}$ 1.802, de 26 de agosto de 2008. Institui o Programa de Educação pelo trabalho para a Saúde - PET-Saúde. Disponível em: <http:/ / www.saude.gov.br/sas/.htm>. Acesso em: 25 out. 2009.

5. Brasil. Ministério da Saúde. Lei no 8.142, de 28 de dezembro de 1990. Lei Orgânica da Saúde. Dispõe sobre a participação da comunidade na gestão do Sistema único de Saúde (SUS) e sobre as transferências intergovernamentais de recursos financeiros na área de saúde, e dá outras providências. Brasília, 1990.

6. Franco AR, Haddad N, Forster AC, Caccia-Bava MCG. A FMRP-USP em atividades de ensino e extensão de serviços à comunidade, dentro do projeto Centro de Saúde-Escola. Medicina, Ribeirão Preto: 35: 425-432, jul./set., 2002.

7. Forster AC. Estudo sobre a formação em atenção primária e medicina de família no curso de medicina da Universidad Autónoma de Madrid, Espanha, 1999/2000. Tese (Livre-Docente). Ribeirão Preto: Faculdade de Medicina de Ribeirão Preto da Universidade de São Paulo, Ribeirão Preto, 2004. 134 p.

8. Gil CRR, Turini B, Cabrera MAS, Kohatsu M, Orquiza SMC. Interação ensino comunidade e serviços: desafios e perspectivas de uma experiência de ensino-aprendizagem na Atenção Básica. Rev Bras Educ Med. 2008;2(2):230-9.

\section{CONTRIBUIÇÃO DOS AUTORES}

Janise Braga Barros Ferreira, Aldaísa Cassanho Forster, José Sebastião dos Santos responsabilizam-se igualmente pelas etapas de concepção teórica, elaboração, discussão, redação e revisão desta produção

\section{CONFLITO DE INTERESSES}

Declarou não haver.

\section{ENDEREÇO PARA CORRESPONDÊNCIA}

Janise Braga Barros Ferreira

Faculdade de Medicina de Ribeirão Preto - USP

Rua Cerqueira César, 845 - apto 101

Centro - Ribeirão Preto

CEP 14010-130 - SP

E-mail: janise@fmrp.usp.br 